\title{
CHRONIC MULTIFOCAL OSTEOMYELITIS
}

\author{
ANDREW J. CARR, WILliaM G. COLE, DONALD M. ROBERTON, C. W. CHOW
}

\section{From the Royal Children's Hospital, Melbourne, Australia}

We describe 22 patients who presented between the ages of 4 and 14 years with gradual onset of malaise and pain at the sites of multiple bone lesions. The symptoms from the bone lesions were sometimes sequential in onset and often relapsing. The radiological findings were typical of osteomyelitis. Radioisotope bone scans identified some clinically silent lesions. Bone biopsies were performed in 20 patients and the changes of osteomyelitis were seen in 17; microbiological culture was positive in only one.

Seven patients had polyarthritis, two had palmoplantar pustulosis and one had psoriasis. Some symptomatic relief was obtained with anti-inflammatory agents and, to a less extent, with antibiotics. No patient had primary immunodeficiency. The mean duration of symptoms from the bone lesions was two years (1 to 4). When arthritis was present the joint symptoms lasted considerably longer (mean 7 years; range 4 to 10). The long-term prognosis was generally good. There was no evidence of altered bone growth or abnormal joint development. One patient developed a progressive kyphosis requiring fusion, but no other surgical intervention was necessary.

J Bone Joint Surg [ Br] 1993; 75-B :582-91.

Received 6 August 1992; Accepted 30 September 1992

Chronic multifocal osteomyelitis is a rare condition of unknown aetiology. The clinical presentation is of the gradual onset of malaise, with local pain and tenderness at the sites of infection. The bone lesions may occur sequentially and are located predominantly in the metaphyses of long bones, but may involve the medial end of the clavicle, a vertebral body or the sacroiliac joint. The condition was first described by Giedion et al (1972) and since then at least 47 cases have been reported

\footnotetext{
A. J. Carr, ChM, FRCS, Clinical Research Fellow

C. W. Chow, FRCPA, Director of Anatomical Pathology

Royal Children's Hospital, Flemington Road, Parkville, Melbourne, Victoria 3052, Australia.

W. G. Cole, MSc, PhD, FRACS, Professor of Orthopaedics

The Hospital for Sick Children, 555 University Avenue, Toronto, Ontario, Canada M5G 1 X8.

D. M. Roberton, MD, FRACP, Professor of Paediatrics

Adelaide Children's Hospital, 72 King William Road, North Adelaide, South Australia 5006, Australia.

Correspondence should be sent to Professor W. G. Cole.

(C)1993 British Editorial Society of Bone and Joint Surgery 0301-620X/93/4561\$2.00
}

under a number of headings, most of them as isolated case presentations (Gustavson and Wilbrand 1974; Willert and Enderle 1977; Probst, Björkstén and Gustavson 1978; Girardet et al 1979; Björkstén and Boquist 1980; Blockey 1983; Meller et al 1984; Murray and Kehl 1984; Gamble and Rinsky 1986; Wiener, Newbold and Merten 1986). None of these reports included comprehensive clinical, histopathological, microbiological and immunological investigations.

The bone lesions are frequently relapsing and may be symmetrical but these features are not essential to the diagnosis. Associations have been reported with palmoplantar pustulosis (Björkstén et al 1978; Bergdahl et al 1979; Benhamou, Chamot and Kahn 1988) and with arthritis (Giedion et al 1972; Probst et al 1978; Benhamou et al 1988). Condensing osteitis of the clavicle presents with many similar features (Brower, Sweet and Keats 1974; Appell et al 1983; Mollan, Craig and Biggart 1984; Jones et al 1990) as does sternocostoclavicular hyperostosis, which is also associated with palmoplantar pustulosis and arthritis (Köhler et al 1975; Sonozaki et al 1981 ; Chigira et al 1986).

We report 22 patients with multifocal osteomyelitis all of whom underwent rigorous investigation and were followed for long periods.

\section{PATIENTS AND METHODS}

Between 1975 and 1989 we diagnosed and treated 22 patients with multifocal osteomyelitis at the Royal Children's Hospital in Melbourne (Table I). The diagnosis was based on the presence of multiple bone lesions typical of osteomyelitis and on the clinical picture of insidious onset of malaise and local pain of relapsing nature and prolonged duration, associated with arthritis or palmoplantar pustulosis. No significant past medical or family history was identified. The mean follow-up was 74.8 months (18 to 168 ).

The response to antibiotics and non-steroidal antiinflammatory agents was assessed from the speed with which symptoms settled after starting treatment: good, within one week; moderate, within one month; slight, within two months; and none, no discernible effect within three months. The patients were treated with the same combination of intravenous and oral flucloxacillin, chloramphenicol and cephalosporins.

Radiography. Plain radiographs were taken of all symptomatic bones and joints and radioisotope bone scans 


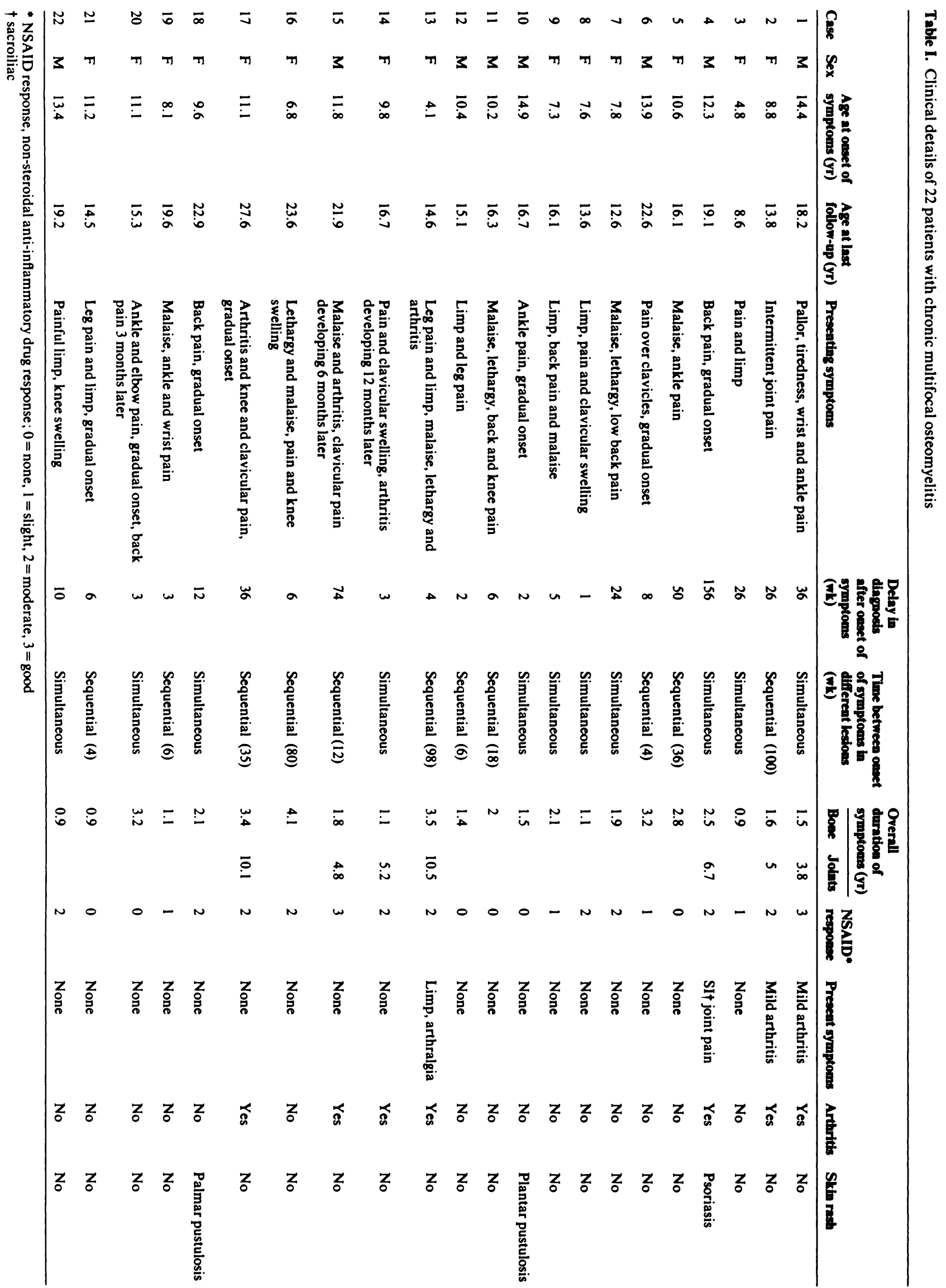


were done in all cases. If clinically silent lesions were identified on the bone scan further radiographs were taken. Repeat radiography was performed at review. If new symptoms developed repeat bone scans were performed.

Laboratory and immunological investigation. The haemoglobin, ESR, and total and differential WBCs were measured. In patients with arthritis, rheumatoid factor, antinuclear factor and HLA-B27 status were also evaluated.

Immunological assessment was performed on a single peripheral blood sample as described previously (Hosking, Fitzgerald and Shelton 1977; Hosking and Roberton 1981). IgG, IgA, and IgM concentrations were measured by nephelometry and expressed as $\mathrm{IU} / \mathrm{ml}$ and as age-related centiles against normal values (Shelton et al 1974). IgE concentrations were measured by radioimmunoassay. Mononuclear leucocytes were separated from heparinised blood on Ficoll-hypaque density gradients and cultured in tissue-culture medium and in autologous serum or fetal calf serum in the presence of three different concentrations of purified phytohaemagglutinin (PHA), pokeweed mitogen (PWM) or concanavalin A (con A) (Hosking and Balloch 1983). They were also cultured using pooled irradiated allogeneic stimulator cells in a mixed lymphocyte reaction. Lymphocyte phenotypes were determined for five patients using OKT3, OKT4 and OKT8 antibodies (Ortho Diagnostics, Systems Inc, New Jersey) and fluoroscein microscopy or fluorosceinactivated flow cytometry. Polymorphonuclear leucocytes (PML) were separated by dextran sedimentation. Metabolic activation of PML in response to stimulation by heat-killed Cowan strain Staphylococcus aureus or Candida albicans was assessed by ${ }^{125} \mathrm{I}$ incorporation into a neutrophil iodination microassay (Roberton et al 1981). Phagocytosis by PML was measured by yeast particle ingestion and neutrophil chemotaxis by using a Boyden chamber technique. Serum protein electrophoresis was also performed.

Histopathology and microbiology. Bone biopsies were done, at various stages of the disease, in 20 patients and were cultured immediately. Specimens were fixed in $10 \%$ buffered formalin, decalcified and processed in the usual way. The sections were stained with haemotoxylin and eosin, periodic acid-Schiff, Gram's stain and the ZiehlNielsen stain for Mycobacterium tuberculosis. Microbiological cultures of the bone biopsies and blood and urine were performed specifically to identify fungi and aerobic and anaerobic bacteria.

\section{RESULTS}

Clinical features. The clinical presentation varied but was usually suggestive of chronic osteomyelitis, with insidious onset of constitutional symptoms and pain localised to the site of the bone lesions (Table I). These were often associated with swelling and local erythema. In ten patients the symptoms were initially localised to one site, and developed at other sites 4 to 100 weeks later. Their mean duration was 2.0 years $\pm 0.9(0.9$ to 4.1$)$, often with a relapsing pattern. Symptoms at a particular lesion never disappeared completely between relapses, but two patients had periods of 20 and 18 weeks completely free from symptoms before developing a lesion at a new site.

An association with arthritis was found in seven patients. In one the arthritis preceded the onset of symptoms from the osteomyelitis, but in the remainder it developed at the same time or after the bone symptoms. None of these patients has developed radiological evidence of arthritis and the symptoms have been restricted to mild or moderate pain in the elbows, wrists, knees and ankles. Response to anti-inflammatory medication was good. None of the patients with arthritis had palmoplantar pustulosis but one had psoriasis of the scalp. The mean duration of joint symptoms was 5.9 years \pm 2.7 (3.5 to 10.5$)$ and the mean duration of the symptoms of osteomyelitis in these patients was 2.2 years \pm 0.9 ( 1.1 to 3.5 years). The mean duration of symptoms from the bone lesions in the whole group was 2.0 years $\pm 0.9(0.9$ to 4.1$)$. Of the three patients with involvement of the sacroiliac joint only one had generalised arthritis.

At review only four patients (cases 1, 2, 4 and 13) still complained of symptoms; all had mild joint discomfort particularly after exercise. No patient complained of pain at the sites of bone lesions but some residual swelling of the bone was common, particularly of the clavicle and distal tibia. There was no clinical or radiological evidence of abnormality of bone growth or epiphyseal arrest. One patient developed a progressive kyphotic deformity at the D5 level and required surgical fusion.

Radiography. The distribution of the bone lesions is shown in Table II. Radiographs of the metaphyseal lesions were typical of osteomyelitis with metaphyseal lucency with or without sclerosis, sometimes extending into the epiphysis (Fig. 1). The epiphyseal lesions gradually filled in and disappeared while the epiphysis continued to grow normally. There were no cases of premature growth arrest. The metaphyseal lesions elongated as the physis grew away from the lesion sometimes leaving only a small area of sclerosis adjacent to the plate (Fig. 2). The pattern of healing was not uniform and a number of lesions healed with residual sclerosis and expansion (Fig. 3). The clavicle, if involved, was always affected at its medial end and had both lucent and sclerotic areas often with some associated periosteal reaction (Fig. 4). Vertebral lesions caused collapse of the body and vertebra plana (Fig. 5). One patient with vertebral involvement developed a progressive kyphosis which required fusion. In the three with involvement of the sacroiliac joint the radiological features were of unilateral periarticular sclerosis, predominantly in the ilium (Fig. 6).

Radioisotope bone scans showed increased uptake in all cases. Nine lesions in eight patients were asympto- 


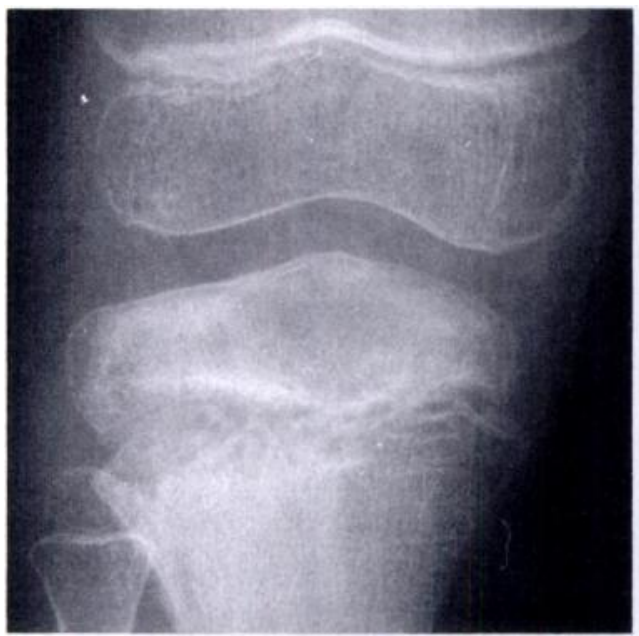

Fig. 1a

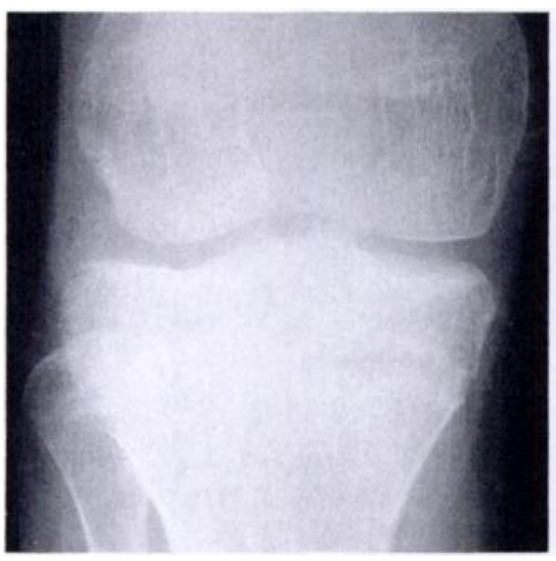

Fig. 1c

Figure 2a - Lateral radiograph of the ankle of a ten-year-old girl showing a lucent metaphyseal lesion with a fine sclerotic margin. Figure 2b - The same ankle two years later. The epiphysis has grown normally, away from the lesion. There are lines of growth arrest around the healed lesion, which had been asymptomatic for 12 months.

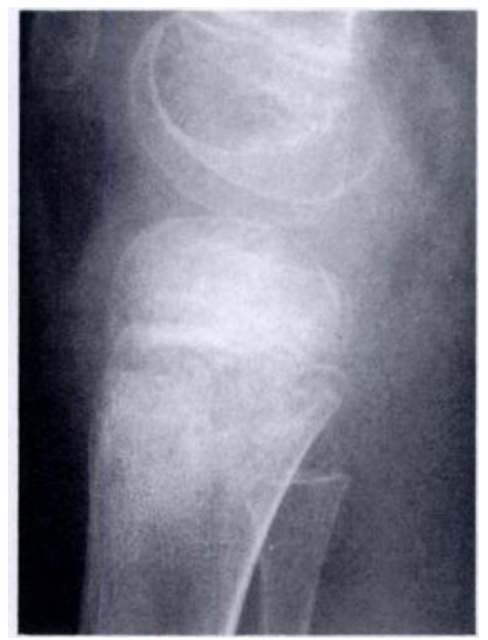

Fig. 1b

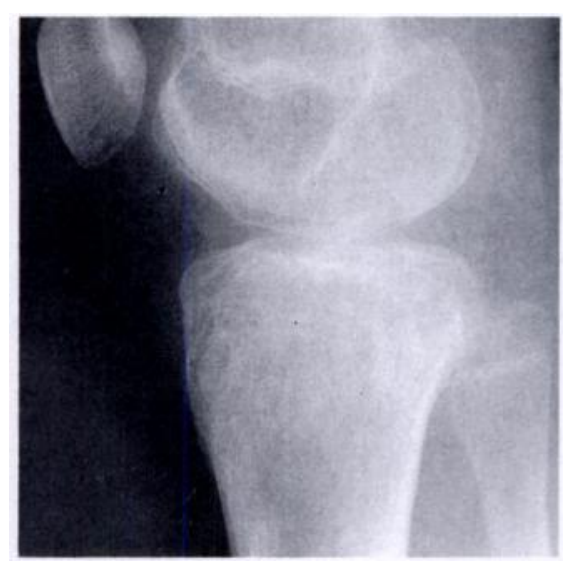

Fig. 1d

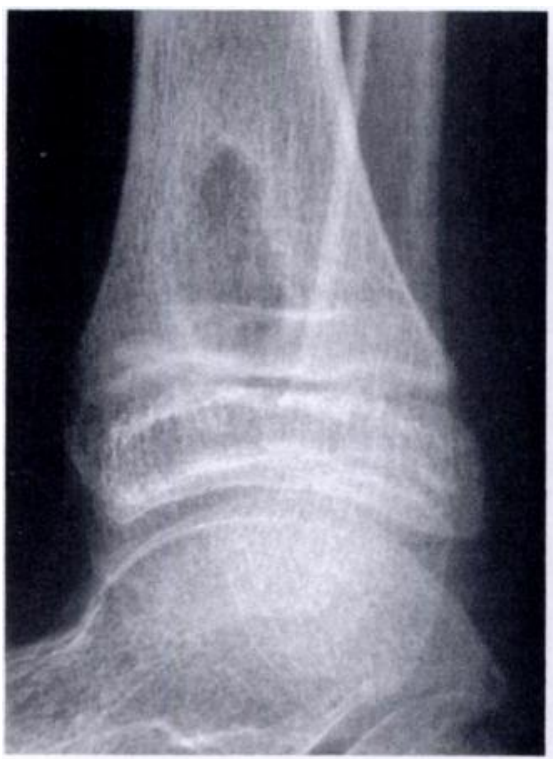

Fig. 2a
Anteroposterior (a) and lateral (b) radiographs of the knee of a six-year-old girl with a radiolucent lesion with sclerotic margins in the proximal metaphysis of the tibia. It extends into the epiphysis.

Anteroposterior (c) and lateral (d) radiographs of the same knee ten years later. A healed metaphyseal lesion is present with residual sclerosis and slight bone expansion. The epiphysis is normal and the growth plate has closed. No evidence of abnormal bone growth was found.

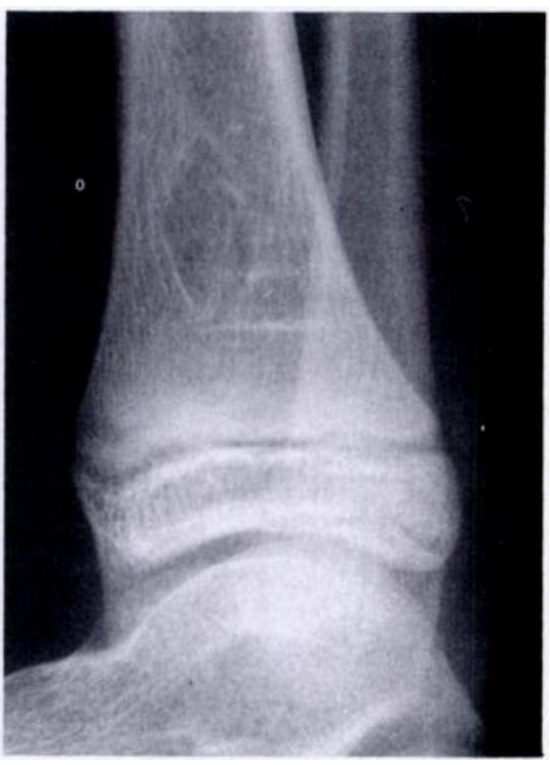

Fig. 2b 


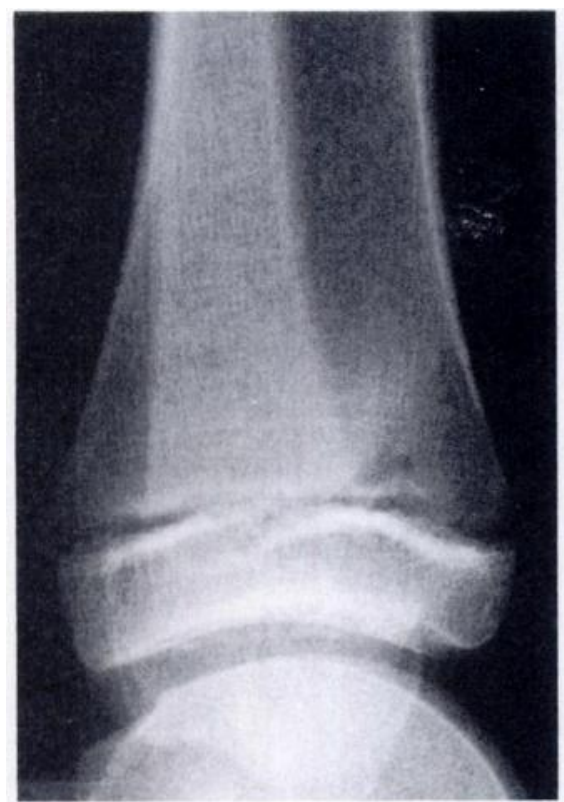

Fig. 3a

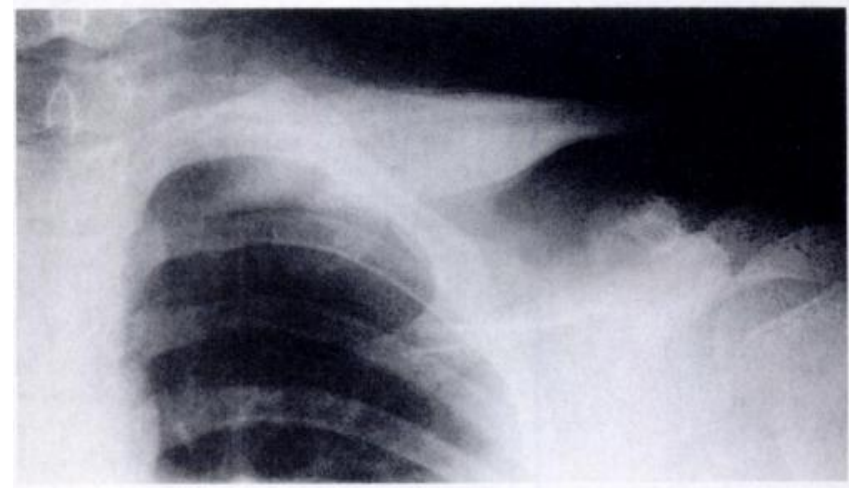

Fig. 4

The left clavicle of a 15-year-old boy, showing sclerotic expansion of the medial end and some periosteal reaction.

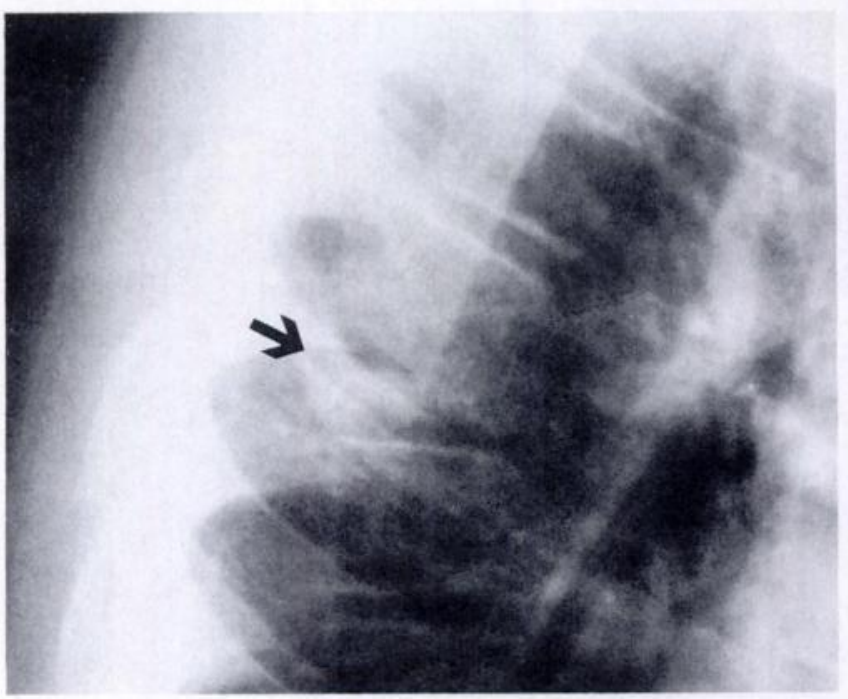

Fig. 5

Lateral radiograph of the thoracic spine of a nine-year-old girl with vertebra plana deformity of the fifth thoracic vertebra (arrow).

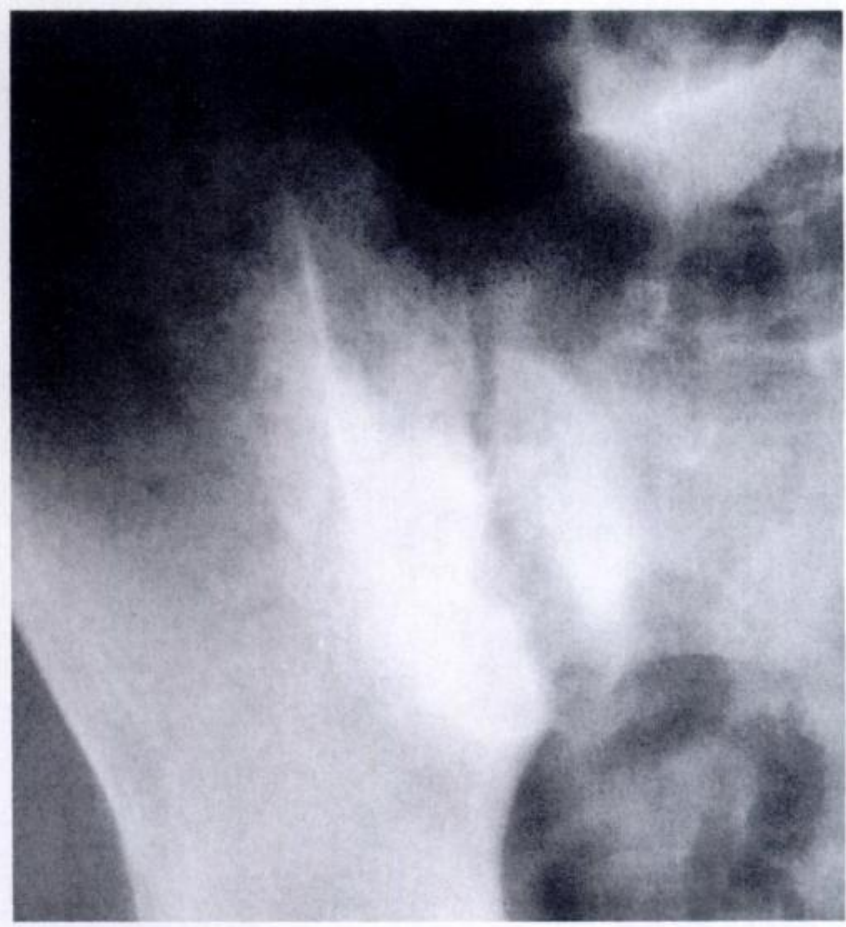

Fig. 6

Radiograph of the pelvis of a 13-year-old girl. The sacroiliac joint is wide and there is periarticular sclerosis.

matic at the time of bone scan and detection of silent lesions in this way may hasten the diagnosis. In one case, no abnormality was evident on the initial plain radiographs and the diagnosis was made only after bone scintigraphy; subsequent plain radiographs showed pathological changes.

Laboratory and immunological investigation. The ESR was elevated in most patients and the total and differential WBCs were normal (Table III). No patient had a 
Table II. Radiological features of 22 patients with chronic multifocal osteomyelitis

\begin{tabular}{|c|c|c|c|c|}
\hline \multirow{2}{*}{ Case } & \multirow{2}{*}{$\begin{array}{l}\text { Interval from } \\
\text { onset of } \\
\text { symptoms (wk) }\end{array}$} & \multirow[b]{2}{*}{ Site of bone lesions } & \multicolumn{2}{|l|}{ Radiological } \\
\hline & & & Features & Outcome \\
\hline 1 & 36 & Bilateral radii & Metaphyseal lucency & Normal \\
\hline 2 & 20 & $\begin{array}{l}\text { D8 to } 10, \text { multiple ribs, proximal tibia (L)*, } \\
\text { sacrum }\end{array}$ & $\begin{array}{l}\text { Metaphyseal lucency and surrounding sclerosis, } \\
\text { vertebra plana }\end{array}$ & Vertebral wedging and kyphosis \\
\hline 3 & 21 & Sacrum*, patella (R), distal femur (L) & $\begin{array}{l}\text { Sacral sclerosis, lucent lesion in the proximal } \\
\text { pole of the patella }\end{array}$ & Lesion healed with sclerosis \\
\hline 4 & 156 & Distal tibia (L)*, D11, SI † joint (R) & Metaphyseal lucency and surrounding sclerosis & Lesion healed with sclerosis \\
\hline 5 & 50 & Distal tibia (L), clavicle (L) & $\begin{array}{l}\text { Expanded lytic lesion in clavicle (medial), } \\
\text { metaphyseal lucency }\end{array}$ & $\begin{array}{l}\text { Healed lesions, clavicular } \\
\text { expansion }\end{array}$ \\
\hline 6 & 8 & Clavicle (L), fibula (L)*, metatarsal (L)* & $\begin{array}{l}\text { Expanded lytic lesions in clavicles (medial) with } \\
\text { periosteal reaction }\end{array}$ & Clavicular expansion \\
\hline 7 & 24 & Sacrum, pubic ramus (L), tibia (L)* & $\begin{array}{l}\text { Metaphyseal lucency with surrounding sclerosis, } \\
\text { sclerosis sacrum }\end{array}$ & Normal \\
\hline 8 & 1 & $\begin{array}{l}\text { Clavicle (L), SI joint }{ }^{*}, C 7 \text {, greater } \\
\text { trochanter (R) }\end{array}$ & $\begin{array}{l}\text { Lytic lesions in clavicle (medial) and greater } \\
\text { trochanter }\end{array}$ & Mild clavicular expansion \\
\hline 9 & 5 & D11-12, acetabulum (L) & Vertebral collapse, pelvic sclerosis & $\begin{array}{l}\text { Pelvic sclerosis, mild vertebral } \\
\text { body wedging }\end{array}$ \\
\hline 10 & 2 & $\begin{array}{l}\text { Metatarsal }(\mathbf{R})^{*}, \text { distal fibula and proximal } \\
\text { tibia (L) }\end{array}$ & Periosteal reaction & Normal \\
\hline 11 & 6 & Distal tibia (L), D5, D8, D9 & Metaphyseal lucency, vertebral collapse & $\begin{array}{l}\text { Lesion healed with sclerosis, } \\
\text { vertebral wedging }\end{array}$ \\
\hline 12 & 2 & Bilateral tibiae (distal) & Metaphyseal lucency with surrounding sclerosis & Healed with some sclerosis \\
\hline 13 & 4 & Distal fibula (L), calcaneum, metatarsal & Lucent lesions & Normal \\
\hline 14 & 3 & Clavicle (L), sternum* & $\begin{array}{l}\text { Ill-defined expanded lucent lesion in clavicle } \\
\text { (medial), metaphyseal lucency }\end{array}$ & Mild clavicular expansion \\
\hline 15 & 74 & Bilateral clavicles & $\begin{array}{l}\text { Lytic lesion in clavicle (medial) with periosteal } \\
\text { reaction }\end{array}$ & $\begin{array}{l}\text { Lesion healed, mild expansion } \\
\text { of bone }\end{array}$ \\
\hline 16 & 6 & Proximal tibia (L), SI joint (R) & $\begin{array}{l}\text { Metaphyseal lucency, sclerotic lesion around SI } \\
\text { joint }\end{array}$ & Normal \\
\hline 17 & 12 & Proximal tibia (L), clavicle (R) & $\begin{array}{l}\text { Metaphyseal lucency, expanded lytic lesion in } \\
\text { clavicle (medial) }\end{array}$ & Normal \\
\hline 18 & 12 & $\begin{array}{l}\text { Multiple thoracic and lumbar vertebral } \\
\text { bodies }\end{array}$ & Vertebral collapse & $\begin{array}{l}\text { Progressive kyphosis requiring } \\
\text { surgical correction }\end{array}$ \\
\hline 19 & 3 & Distal tibia, distal radius & Metaphyseal lucency & Normal \\
\hline 20 & 3 & $\begin{array}{l}\text { Distal tibia (L), distal humerus (R), } \\
\text { SI joint (R)* }\end{array}$ & Metaphyseal lucency with surrounding sclerosis & Lesions healed with sclerosis \\
\hline 21 & 4 & Proximal and distal tibia (R) & Metaphyseal lucency with surrounding sclerosis & Lesions healed with sclerosis \\
\hline 22 & 10 & Proximal femur (R) and tibia (R) & Metaphyseal lucency with surrounding sclerosis & Lesions healed with sclerosis \\
\hline
\end{tabular}

* initially asymptomatic

$\uparrow$ sacroiliac

deficiency of any immunoglobulin isotype. Three had IgM concentrations above the 95th centile for their age; four had IgA and one had IgG concentrations above this range. The IgE concentrations were all within the normal range.

There were no significant abnormalities of the responses of separated mononuclear cells in culture to the mitogens PHA, PWM or con A, or to pooled allogeneic cells. One patient had a deficient mononuclear cell response to all three mitogens but normal responses to allogeneic cells. All responses, however, were normal on subsequent testing. Polymorphonuclear leucocyte iodination assays with Staphylococcus aureus and Candida albicans did not reveal any abnormalities of oxidative metabolism of phagocytic cells. Neutrophil chemotaxis was marginally low in one patient on initial testing but was normal subsequently. The median chemotaxis result, expressed as a percentage of normal control neutrophils, was 108. Polymorphonuclear leucocyte phagocytosis was normal (median 3.1 yeast particles/cell).

No patient was lymphopenic at the time of testing; the median lymphocyte count was $2465 / \mu l$ (2010 to 3168 ). 
Table III. Laboratory and immunological findings

\begin{tabular}{|c|c|c|c|c|c|}
\hline Case & $\begin{array}{l}\text { Interval from onset } \\
\text { of symptoms (wk) }\end{array}$ & $\begin{array}{l}\text { ESR } \\
(\mathrm{mm} / \mathrm{hr})\end{array}$ & ASOT* & $\begin{array}{l}\text { White cell } \\
\text { count }\end{array}$ & $\begin{array}{l}\text { Immunoglobalinst } \\
\text { (IU/ml) }\end{array}$ \\
\hline 1 & 36 & 130 & 120 & 10300 & IgA (343), IgG (398) \\
\hline 2 & 36 & 55 & 30 & 5400 & IgA (303), IgM (237) \\
\hline 3 & 28 & 66 & 15 & 4300 & Normal $\ddagger$ \\
\hline 4 & 156 & 32 & & 7900 & \\
\hline 5 & 50 & 39 & 240 & 9300 & IgM (184) \\
\hline 6 & 26 & & 60 & 8500 & IgA (201) \\
\hline 7 & 16 & 42 & 30 & 9000 & Normal \\
\hline 8 & 4 & 44 & $<15$ & 6600 & Normal \\
\hline 9 & 5 & 53 & $<15$ & 5200 & Normal \\
\hline 10 & 4 & 91 & 40 & 5800 & \\
\hline 11 & 6 & 88 & 260 & 10000 & \\
\hline 12 & 2 & 6 & & 4700 & IgM (168) \\
\hline 13 & 17 & 34 & 120 & 7000 & IgA (177) \\
\hline 14 & 20 & 26 & 60 & 5200 & Normal \\
\hline 15 & 74 & 80 & & 7800 & \\
\hline 16 & 6 & 73 & 30 & 7300 & Normal \\
\hline 17 & 12 & 29 & & 8700 & Normal \\
\hline 18 & 12 & 53 & 30 & 5600 & Normal \\
\hline 19 & 12 & 14 & & 6400 & Normal \\
\hline 20 & 12 & 19 & 40 & 3800 & \\
\hline 21 & 10 & 44 & 30 & 4500 & \\
\hline 22 & 10 & 20 & 40 & 7200 & \\
\hline
\end{tabular}

No patient was neutropenic. In the five patients in whom lymphocyte phenotyping had been performed, the absolute numbers (and ranges) of CD3, CD4 and CD8 positive cells respectively were $1722 / \mu \mathrm{l}$ ( 369 to 2194$), 798 / \mu \mathrm{l}$ (335 to 1354 ) and $743 / \mu \mathrm{l}$ (34 to 861 ). The median CD4 to CD8 ratio was 1.4 . Serum protein electrophoresis showed no significant changes. None of the nine patients tested were HLA-B27 positive nor did they have a positive antinuclear or rheumatoid factor.

Histopathology. In 17 of the 20 cases biopsied, histopathological examination showed changes suggestive or diagnostic of osteomyelitis (Table IV). In three the bone was normal, or showed only mild non-specific changes, including focal fibrosis, woven bone, or periosteal new bone formation. Inflammatory infiltration was not seen. In the four cases suggestive of osteomyelitis there were small foci of fibrosis associated with moderate numbers of plasma cells. Although consistent with osteomyelitis such changes are not infrequently seen adjacent to non- infective lesions, such as osteoid osteoma. In all four cases, synovium biopsied at the same time showed synovitis. In one this was initially suppurative, but chronic villous synovitis was present on rebiopsy two years later. In the other two chronic villous synovitis was seen. In the biopsies considered to be diagnostic of osteomyelitis there was extensive fibrosis with intense focal infiltration by plasma cells, often with variable numbers of lymphocytes and histiocytes. In addition, necrotic bone, granulomas and suppurative or marked PML infiltration in various combinations were seen in many cases. The granulomas were often tuberculoid, particularly around dead bone. Caseation and acid-fast bacilli were not seen.

Microbiology. Microbiological investigation produced only one positive culture from a bone biopsy with moderate growth of Staphylococcus aureus (Table IV). The remaining bone cultures and all the blood and urine cultures for bacteria, fungi and mycobacteria were 
negative. The single patient with a positive culture was similar, in other respects, to the rest of the group with gradual onset of symptoms and multifocal lesions.

The response to antibiotics in this patient was moderate and her symptoms settled completely ten months after their onset and have not recurred. In one case repeated flare-ups of symptoms from a proximal tibial lesion appeared to respond to the administration of flucloxacillin. In the remainder the response to antibiotics was slight or none.

\section{DISCUSSION}

The term chronic multifocal osteomyelitis seems most appropriate to describe this heterogeneous group of signs and symptoms for which no cause is known. The lesions can be symmetrical and relapsing but these features are not essential to the diagnosis. The condition has also been described as recurrent but this was not true of this series of patients. It is slightly more common in girls than boys as in chronic unifocal osteomyelitis (Cole 1991), but in contrast to acute osteomyelitis, which most commonly affects boys. We did not find the marked female preponderance described by other authors (Pelkonen et al 1988).

A spectrum of presenting features is possible, ranging from bone lesions alone or combined with arthritis, palmoplantar pustulosis or psoriasis. It seems unlikely that the varying combinations represent a single clinical entity with a common aetiology. The skin lesions do appear to follow the same relapsing course shown by the bone lesions but the significance of the association with palmoplantar pustulosis is unclear. The arthritis seen in this condition is not entirely typical of juvenile rheumatoid arthritis; morning stiffness is not a feature and there is no radiological evidence of joint abnormality

Table IV. Histological and microbiological findings of bone biopsies

\begin{tabular}{|c|c|c|c|c|c|c|c|c|c|c|c|}
\hline \multirow[b]{2}{*}{ Case } & \multirow{2}{*}{$\begin{array}{l}\text { Interval from onset of } \\
\text { symptoms (wk) }\end{array}$} & \multicolumn{6}{|c|}{ Histology ${ }^{*}$} & \multicolumn{3}{|c|}{ Microbiologyt } & \multirow{2}{*}{$\begin{array}{l}\text { Antibiotic } \\
\text { responset }\end{array}$} \\
\hline & & $\mathbf{A}$ & B & $\mathbf{C l}$ & $\mathbf{C 2}$ & $\mathbf{C 3}$ & $\mathrm{C} 4$ & Bone & Blood & Urine & \\
\hline 1 & 38 & & & * & & & & 0 & 0 & $\mathbf{0}$ & 0 \\
\hline 2 & 20 & & & * & * & & $*$ & $\mathbf{0}$ & 0 & $\mathbf{0}$ & $\mathbf{0}$ \\
\hline 3 & 28 & * & & & & & & 0 & 0 & 0 & 1 \\
\hline 4 & 156 & & & not & done & & & not done & 0 & 0 & 0 \\
\hline 5 & 54 & & * & & & & & 0 & 0 & 0 & 1 \\
\hline 6 & 12 & & & * & $*$ & $*$ & * & 0 & 0 & 0 & 1 \\
\hline 7 & 56 & * & & & & & & $\mathbf{0}$ & $\mathbf{0}$ & 0 & 0 \\
\hline 8 & 5 & & & & $*$ & * & $*$ & 0 & 0 & 0 & 0 \\
\hline 9 & 9 & & * & & & & & 0 & 0 & 0 & 0 \\
\hline 10 & 11 & & & * & & * & $*$ & 0 & 0 & 0 & 1 \\
\hline 11 & 3 & & & not & done & & & not done & $\mathbf{0}$ & $\mathbf{0}$ & 2 \\
\hline 12 & 56 & & & * & & & $\bullet$ & 0 & 0 & $\mathbf{0}$ & 1 \\
\hline 13 & 7 & & * & & & & & 0 & $\mathbf{0}$ & $\mathbf{0}$ & 0 \\
\hline 14 & 3 & & & $\cdot$ & $\bullet$ & $\bullet$ & $*$ & 0 & 0 & 0 & 0 \\
\hline 15 & 74 & & & $\bullet$ & $*$ & $*$ & $*$ & 0 & 0 & 0 & 0 \\
\hline 16 & 44 & & * & & & & & 0 & 0 & 0 & 0 \\
\hline 17 & 20 & * & & & & & & 0 & 0 & 0 & 0 \\
\hline 18 & 16 & & & & & & 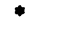 & 0 & 0 & 0 & 0 \\
\hline 19 & 12 & & & * & & * & • & 0 & 0 & 0 & 0 \\
\hline 20 & 12 & & & & & * & $*$ & 0 & 0 & 0 & 1 \\
\hline 21 & 4 & & & $*$ & * & & $*$ & 2 (S. aureus) & 0 & 0 & 1 \\
\hline 22 & 12 & & & & * & $*$ & $*$ & 0 & 0 & 0 & 1 \\
\hline
\end{tabular}

- $A=$ Bone normal or changes minimal. $B=$ Suggestive of osteomyelitis; fibrosis with mild to moderate round cell infiltration. $\mathrm{C}=$ Diagnostic of osteomyelitis. $\mathbf{C l}=$ Numerous neutrophils. $\mathbf{C 2}=$ Granulomas. $\mathrm{C} 3=$ Necrotic bone. $\mathrm{C} 4=$ Fibrosis with intense round cell infiltration. $\dagger 0=$ No growth, $1=$ Slight, $2=$ Moderate, and $3=$ Heavy growth .

$\ddagger 0=$ none, $1=$ slight, $2=$ moderate, and $3=$ good. 
either at presentation or at long-term follow-up. Nor are there any serological changes to suggest an autoimmune process.

We investigated 15 patients rigorously for evidence of immunodeficiency but did not find a primary abnormality. Six had some elevation of immunoglobulin levels consistent with an inflammatory response. Björkstén et al (1978) did not find any immunological abnormality in four patients.

Although the radiological and histological appearances were invariably typical of osteomyelitis, microbiological investigation produced a positive culture in only one case. This patient presented with a typical picture of two distinct bone lesions and Staphylococcus aureus was cultured from bone biopsy.

At the other end of the spectrum one patient presented with arthritis and only developed symptoms from bone lesions six months later. With such a diversity of presentation it is not surprising that delays in diagnosis still occur and we outline below guidelines for the diagnosis, treatment and prognosis of the disorder.

Diagnosis. The presentation is invariably gradual; local pain, tenderness, swelling and erythema often accompany the bone lesions but may be absent if the spine or pelvis is involved. Plain radiographs usually reveal features suggestive of osteomyelitis but these may be difficult to detect in the spine or pelvis. The diagnosis of multifocal osteomyelitis can be made only when more than one lesion has occurred and the sequential nature of some lesions can produce a delay in diagnosis. Radioisotope bone scans assist in establishing the diagnosis and in identifying lesions that are initially clinically silent. The diagnosis should be suspected, even if only one bone lesion is present, in the presence of palmoplantar pustulosis, psoriasis or arthritis. Morning stiffness is not a typical feature and the joint pains are often worse at night or after exertion. Histological examination of biopsy tissue is important to exclude other diagnoses, such as tumours or histiocytosis. Although the histology in most cases was typical of osteomyelitis a positive culture was obtained from only one bone biopsy. Failure to identify an organism is not uncommon in cases of chronic osteomyelitis (Cole 1991). Two other cases with positive cultures have been reported. In one Propionibacterium (Le Goff et al 1985) and in the other Mycobacterium (Hummell et al 1987) were identified; these findings emphasise the importance of obtaining a biopsy to exclude an identifiable and treatable infection. It may be appropriate also to look for the presence of atypical mycobacteria and to determine HIV antibody status in some patients. Chronic multifocal osteomyelitis predominantly affects children, whereas sternocostoclavicular hyperostosis, which has many similarities, affects an older age group and may represent the adult form of the disorder.

Treatment. The basis of treatment is expectant. Nonsteroidal anti-inflammatory agents may provide some symptomatic relief, particularly for patients with joint involvement and painful bone symptoms. Antibiotics can also be beneficial but their effect is less predictable. A therapeutic trial may be of value; if symptoms persist unchanged after two weeks of treatment then relief is unlikely with further therapy. We have not used steroids as some authors have suggested (Björkstén et al 1978). Surgical removal of both clavicles has been performed for the treatment of pain in sternocostoclavicular hyperostosis, but the hyperostosis recurred in several of these patients (Sonozaki et al 1981; Abe et al 1984). In chronic multifocal osteomyelitis surgical treatment is rarely necessary.

Prognosis. The symptoms from the bone lesions are often prolonged and relapsing, lasting up to five years. If they settle completely for three months or more, they are unlikely to recur. New lesions, however, can develop up to two years after the onset of symptoms. The prognosis is generally good with residual bone swelling being the commonest sequel, but progressive kyphosis and premature epiphyseal growth arrest are possible (Pelkonen et al 1988). Angular deformities of long bones have also been described but these result from sclerosing lesions of the diaphysis and not from the metaphyseal lesions typical of this condition (Blockey 1983). Joint symptoms tend to be more prolonged and may be present for ten or more years. The arthritis is not associated with clinical or radiological evidence of joint destruction and once the joint symptoms have settled function is normal.

We are grateful for the assistance of Dr David Hill with the care of some of these patients and for the collaboration of Dr Don Bliss in the early part of the study. We are also grateful to the members of the orthopaedic department who contributed cases to the study.

No benefits in any form have been received or will be received from a commercial party related directly or indirectly to the subject of this article.

\section{REFERENCES}

Abe Y, Funayama K, Iwai K, Irei O. An analysis of sternocostoclavicular hyperostosis: report of 27 cases. Orthop and Traumat Surg 1984; 27:749-53.

Appell RG, Oppermann HC, Becker W, et al. Condensing osteitis of the clavicle in childhood: a rare sclerotic bone lesion. Pediatr Radiol $1983 ; 13: 301-6$

Benhamou CL, Chamot AM, Kahn MF. Synovitis-acne-pustulosis hyperostosis-osteomyelitis syndrome (Sapho): a new syndrome among the spondyloarthropathies? Clin Exp Rheumatol 1988; 6:109-12.

Bergdahl K, Bjorksten B, Gustavson KH, Liden S, Probst F. Pustulosis palmo plantaris and its relation to chronic recurrent multifocal osteomyelitis. Dermatologica 1979; 159:37-45.

Björkstén B, Boquist L. Histopathological aspects of chronic recurrent multifocal osteomyelitis. J Bone Joint Surg $[\mathrm{Br}] 1980 ; 62-\mathrm{B}$ : 376-80.

Björkstén B, Gustavson KH, Eriksson B, Lindholm A, Nordström S. Chronic recurrent multifocal osteomyelitis and pustulosis palmoplantaris. J Pediatr 1978; $93: 227-31$.

Blockey NJ. Chronic osteomyelitis: an unusual variant. $J$ Bone Joint Surg $[B r] 1983 ; 65-B: 120-3$.

Brower AC, Sweet DE, Keats TE. Condensing osteitis of the clavicle: a new entity. Am J Roentgenol 1974; $121: 17-21$. 
Chigira M, Maehara S, Nagase M, Ogimi T, Udagawa E. Sternocostoclavicular hyperostosis: a report of nineteen cases, with special reference to etiology and treatment. J Bone Joint Surg [Am] 1986; 68-A :103-12.

Cole WG. The management of chronic osteomyelitis. Clin Orthop 1991; $264: 84-9$.

Gamble JG, Rinsky LA. Chronic recurrent multifocal osteomyelitis: a distinct clinical entity. J Pediatr Orthop 1986; 6:579-84.

Giedion A, Holthusen W, Masel LF, Vischer D. Subacute and chronic 'symmetrical' osteomyelitis. Ann Radiol (Paris) 1972; 15:329-42.

Girardet JP, Sambucy F, Douillet $P$, et al. Ostéomyélite symmétrique subaiguë. Arch Fr Paediatr 1979; 36:418-22.

Gustavson KH, Wilbrand HF. Chronic symmetric osteomyelitis: report of a case. Acta Radiol [Diagn] 1974; 15:551-7.

Hosking CS, Fitzgerald MG, Shelton MJ. The immunological investigation of children with recurrent infections. Aust Paediatr J 1977; 13(suppl):61-9.

Hosking CS, Roberton DM. The diagnostic approach to recurrent infections in childhood. Clin Imunol Allergy 1981; 1 :631-9.

Hosking CS, Balloch A. A formula to assess lymphocyte responsiveness in vitro. Birth Defects 1983; 19:21-3.

Hummell DS, Anderson SJ, Wright PF, Cassell GH, Waites KB. Chronic recurrent multifocal osteomyelitis: are mycoplasmas involved? N Eng J Med 1987; 317:510-11.

Jones MW, Carty H, Taylor JF, Ibrahim SK. Condensing osteitis of the clavicle: does it exist? J Bone Joint Surg [Br] 1990; 72-B:464-7.

Köhler H, Uehlinger E, Kutzner J, et al. Sterno-kosto-klaviculäre Hyperostose. Dtsch Med Wschr 1975; 100:1519-23.
Le Gof P, Brousse A, Fauquert P, Guillet G, Le Roy JP. Arthropathies érosives thoraciques antérieures et intervertébrales associees à la pustulose palmo plantaire. Rev Rheum 1985; 52:391-6.

Meller Y, Yagupsky P, Elitsur Y, Inbar-Ianay I, Bar-Ziv J. Chronic multifocal symmetrical osteomyelitis: report of two cases in Bedouin infants. Am J Dis Chil 1984; 138:349-351.

Mollan RAB, Craig BF, Biggart JD. Chronic sclerosing osteomyelitis: an unusual case. J Bone Joint Surg [ Br] 1984; 66-B:583-5.

Murray SD, Kehl DK. Chronic recurrent multifocal osteomyelitis: a case report. J Bone Joint Surg [Am] 1984; 66-A :1110-2.

Pelkonen P, Ryöppy S, Jaaskelainen J, et al. Chronic osteomyelitislike disease with negative bacterial cultures. Am J Dis Children 1988; $142: 1167-73$.

Probst FP, Björkstén B, Gustavson KH. Radiological aspect of chronic recurrent multifocal osteomyelitis. Ann Radiol (Paris) 1978; $21: 115-25$.

Roberton DM, Dhanjal NK, Levinsky RI, Mowbray JF, Turner MW. Polymorphonuclear neutrophil iodination response as an estimate of defective yeast opsonization. Clin Exp Immunol 1981; 43: 208-14.

Shelton MJ, Meek F, Goller I, Hosking CS. Serum immunoglobin levels in children. Aust J Med Technol 1974; 5:113-7.

Sonozaki H, Mitsui H, Miyanaga Y, et al. Clinical features of 53 cases with pustulotic arthro-osteitis. Ann Rheum Dis 1981; 40:547-53.

Wiener D, Newbold R, Merten D. Chronic recurrent multifocal osteomyelitis. Amer J Roentgenol 1986; 146:87-8.

Willert H-G, Enderle A. Multifocale, symmetrische, chronische osteomyelitis. Arch Orthop Unfall Chir 1977; 89:109-13. 